\title{
Secondary Preventive Health Behavior
}

\author{
John R.C. Wheeler, Ph.D. \\ School of Public Health \\ The University of Michigan \\ Thomas G. Rundall, Ph.D. \\ Cornell University
}

\begin{abstract}
A comprehensive model of secondary preventive health behavior, defined as the use of physician services for preventive care, is constructed which specifies the interrelationships among people's health beliefs, their health status, their accessibility to care, their sociodemographic characteristics, and their use of services. The model is tested by applying path analysis to a household survey of adult residents of Washtenaw County, Michigan. The results support the contention that many factors influence secondary preventive utilization, some principally directly and some largely indirectly through their effects on other variables. Accessibility to care, health status, health beliefs, and sex all directly influence use, while education and age have indirect effects. Income has indirect effects on use which, because they are in opposing directions, cancel each other out.
\end{abstract}

The promotion of health promotion as a social policy requires that individuals engage, essentially, in two sorts of behavior with respect to their health. First, people are encouraged to engage in activities which may have positive influences on their health and to refrain from engaging in activities which may have negative influences. Second, people are encouraged to have their health status professionally monitored so that deleterious changes can be detected and treated as soon as possible. The first sort of behavior might be considered primary preventive behavior, because its principal objective is the prevention of an onset of disease. Similarly, the second type of behavior might be considered secondary preventive health behavior, because its principal objective is the prevention, through medical treatment, subsequent behavioral

Data for this study were collected by the Health Services Research Center at the University of Michigan. The authors wish to express their gratitude to Beverly C. Payne, M.D., Director of the Center, William Horvath, Ph.D. Principal Investigator, and T.E. Dielman, Ph.D., Project Director. We also thank two anonymous reviewers for their thoughtful comments. Funds to support this study were provided by the Arkell Hall Foundation. 
changes, or both, of further reductions in health status. In another respect the two types of behaviors differ. Primary preventive health behavior is almost completely controlled by the individual, subject, of course, to the constraints of his or her social and economic situations. Secondary preventive health behavior, on the other hand, involves an interaction between the individual and a health care provider. This paper focuses on secondary preventive health behavior, presenting a model for explaining the use of physicians' services for preventive care.

\section{FRAMEWORKS FOR MODELING SECONDARY PREVENTIVE HEALTH BEHAVIOR}

At least three different perspectives have been used in the past to model the causal processes related to use of preventive health services: sociodemographic, economic, and social psychological.

\section{Sociodemographic Approach}

The sociodemographic approach examines the role that factors such as age, education, and race have on secondary preventive health behavior. Researchers typically leave the underlying premise of the sociodemographic approach ambiguous. Coburn and Pope have identified six of the most common processes implicitly used to link sociodemographic factors with preventive health behavior: childhood socialization, social participation, work orientation, work constraints, powerlessness, and availability of health education.' The basic argument is that individuals with certain sociodemographic characteristics are more likely to be constrained by one or another of these processes and, thereby, to use less preventive care.

\section{Economic and Social Psychological Approaches}

From both the economic and the social-psychological perspectives the causal process at work is more clearly specified: a person will undertake preventive activity if the perceived benefits to him or her exceed the perceived costs of such activity. Financial barriers, psychological barriers, and barriers associated with the expenditure of time comprise costs which must be borne when preventive behavior is undertaken. With respect to secondary preventive behavior, the benefits are associated with one's perceptions of being threatened by illness and with one's estimation of the ability of early detection and treatment, including subsequently altered behavior, to reduce that threat. 
Curiously, studies of preventive behavior to date have tended to focus on one or another of these perspectives, but typically have not attempted to ascertain how they interact. Hence, the work of those in the tradition of the social demographer has examined the roles of socioeconomic status, sex, and other personal characteristics of consumers on their use of preventive health care.' The work of health behaviorists has looked at the relationship of people's health beliefs, which principally consist of perceived benefits and dangers associated with care, to their use of services. ${ }^{2}$ In contrast, the work of economists and others has focused on the effect of the various prices people must pay on their use, including money price, time price, and costs associated with overcoming other barriers (although some of the work in this area has attempted to relate the price of preventive health care to sociodemographic characteristics of individuals). ${ }^{3-6}$

\section{Integrative Models}

Efforts to integrate these three perspectives were undertaken by various researchers throughout the past decade. A conceptual approach to health services utilization originally specified by Andersen' and later modified by Andersen and Newman ${ }^{8}$ has provided the framework for much of this research. The model posits that a person's decision to seek medical care and the volume of services received depends on: 1) the predisposition of the individual to use services (predisposing factors); 2 ) the individual's ability to secure services (enabling factors); 3 ) the person's need for medical care (need factors). There have been several multivariate studies using large samples designed empirically to assess the effects of predisposing, enabling and need factors on use of health services. ${ }^{9-12}$ Other studies, while not explicitly testing the behavioral model described above, include many of the same variables in their analyses. ${ }^{13.15}$ As Mechanic has noted, results from these studies have been somewhat disappointing. ${ }^{16}$

It is beyond the scope of this paper to review in depth those findings (see Shortell' ${ }^{7}$ ), but several consistencies are apparent and should be noted. First, the amount of explained variance attributable to these models is relatively low. Although Kronenfeld " and Berki and Ashcraft ${ }^{15}$ report around 40 percent explained variance with use of ambulatory care as the dependent variable, other analyses of use of treatment services report from eight to 25 percent variance explained. With the exception of the study of Berki and Ashcraft, whose model explains 30 percent, the amount of variance explained when use of preventive health services is the dependent variable is even lower, ranging from five to 18 percent. Second, the primary factors which explain variation in use of treat- 
ment services are health status (need) and whether one has a usual source of care (enabling). Predisposing characteristics have generally been shown to be weak predictors of use of treatment services. Third, the importance of predisposing factors and income increases when use of preventive health services is the dependent variable.

In summary, the behavioral model has helped researchers structure their thinking and guide the selection of analytic variables, but empirical tests of the model have yielded modest results. This is particularly true of studies of use of preventive health services. Although we do not entirely agree with Wolinksy's conclusion that "any causal models derived from generic frameworks such as Andersen and Newman's. . are left unsupported by these data,"12 we do believe that it would perhaps be wise at this point to step back a bit from Andersen and Newman's general framework and to develop models targeted to specific types of utilization. As Hershey, et al., have noted, the processes by which individuals decide to use and continue to use treatment services, primary and secondary preventive care are likely to differ. ${ }^{14}$ Consistent with this argument, it is our intent to build on the work reviewed above in an effort to develop and test a complex model of how sociodemographic characteristics, economic constraints and perceptions interact to determine use of secondary preventive services.

\section{A MODEL SPECIFIC TO SECONDARY PREVENTIVE HEALTH BEHAVIOR}

Figure 1 depicts our model of secondary preventive health behavior, or use of physician services to monitor health status, indicating the hypothesized manner in which the variables interrelate. Use is specified to be directly determined by people's perceptions. This portion of the specification embodies the core of the health belief model, in which an individual's perceptions of susceptibility to and severity of illness and of the efficacy of preventive services are prime determinants of preventive services use. ${ }^{2.18 .19}$ Several investigators have reported results confirming the importance of these perceptions as determinants of the use of preventive services. ${ }^{19.20}$

The model also specifies use to be a direct result of whether or not a person has a usual source of care. This specification derives from the system barriers theory, ${ }^{21}$ which holds that use of medical care services, perhaps especially use of preventive services, is strongly affected by the magnitude of the barriers which must be overcome. That is, there are monetary, psychological, and temporal costs associated with overcoming barriers to the receipt of ser- 


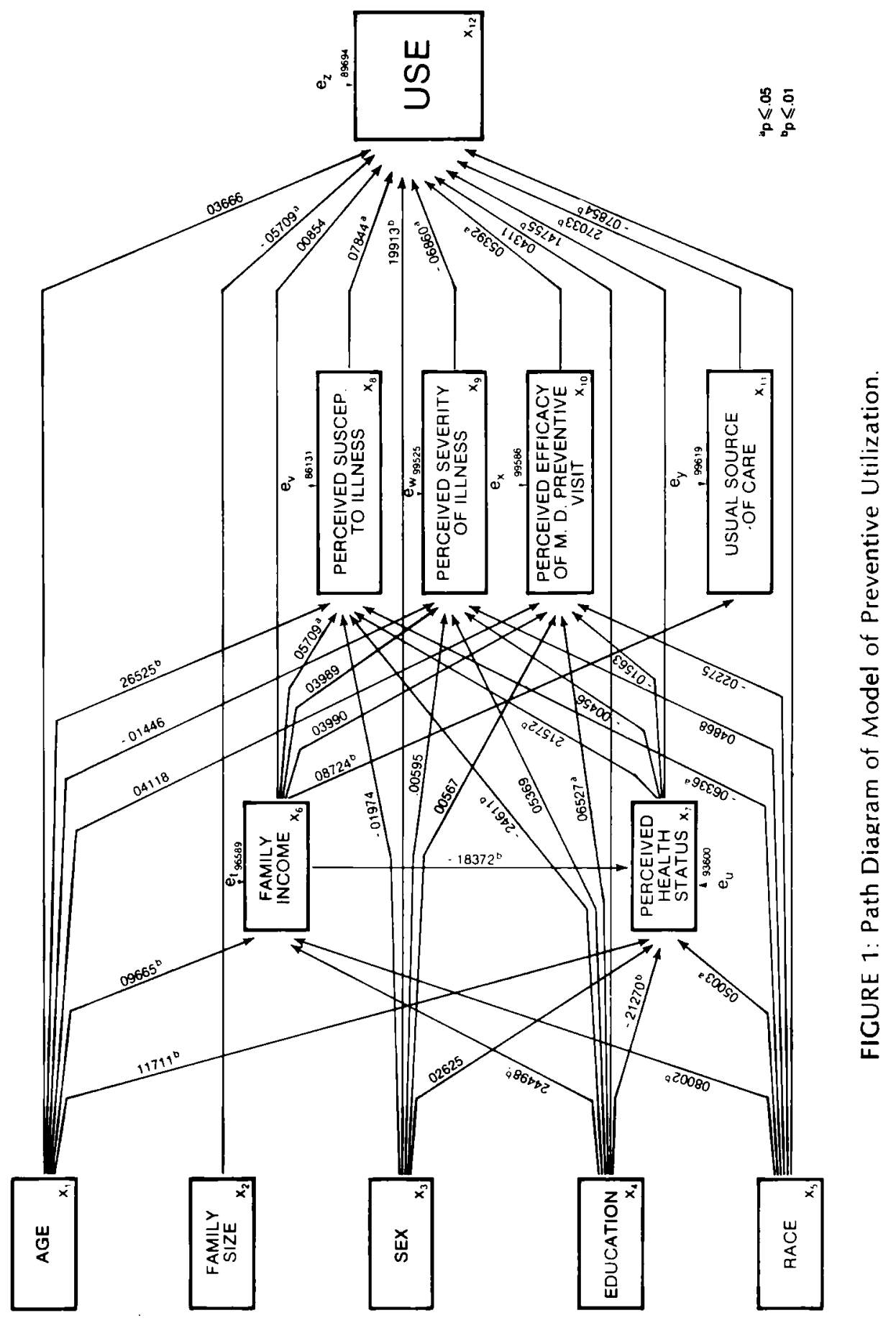


vices, and people will choose to incur these costs only if their assessments of the benefits of the services, in part as reflected in their health beliefs, is sufficiently high. A recent paper by Wan and Gray ${ }^{22}$ has provided support for this theory. In a study of use of preventive services by urban children, they found that frequency of receipt of both immunizations and physical examinations was related to whether the child had a usual source of care. Furthermore, preventive utilization was far less influenced by the particular kind of usual source of care than by the presence or absence of usual source in general.

According to standard microeconomic theory, as a person's income rises he or she typically will consume larger quantities of normal goods because the financial constraints faced by the person have become less restrictive. The extent to which consumption increases with income, i.e., the income elasticity of demand, depends upon, among other things, whether the good is a luxury or a necessity and whether the price of the good is high, relative to the individual's income. Many observers believe that medical care in general is a necessary good and hence that its consumption is not strongly influenced by changes in income. Others feel differently and have produced evidence from cross-sectional studies to support their contentions. ${ }^{23-25}$ Preventive medical care in particular is usually viewed as less necessary but also less costly than other kinds of medical care. From a theoretical perspective these two characteristics of low cost and low necessity have opposing effects on the income elasticity of demand. Hence, we are left with the hypothesis that income and preventive care use are positively related, but that the strength of the relationship is not clear.

Also, not well specified in earlier attempts to relate income to the use of preventive medical care is the complete manner in which income affects use. We hypothesize that income determines use of preventive services in four general ways: 1) directly, by reducing financial constraints; 2) indirectly, by affecting people's health beliefs; 3 ) indirectly, by affecting people's access to preventive services; and 4) indirectly, by influencing people's health status.

The fact that higher income individuals tend to also be in better health has been well documented. ${ }^{26}$ What is important to note, however, is that the causal relationship between income and health is not entirely understood. The relationship may be viewed as circular with the poor becoming ill, thus because they are ill, their capacity to work diminishes and they become even poorer. This is the view taken by Luft. ${ }^{27}$ He concludes from his analysis that although there is some causal relationship from poverty to illness, the effects of poor health on income are more pervasive and account for a substantial portion of the poverty in the United 
States. Other researchers emphasize the effect of poverty on health status. ${ }^{28}$ While we are sympathetic with Luft's argument, with cross-sectional data it seems more reasonable to posit a causal relationship from income to health status. An implicit aim of utilization research is to find policy variables which can be manipulated to achieve greater equity in health services utilization. We argue that the structure of income distribution is an important policy variable and, therefore, we place emphasis here on the causal relationship from income to health status.

Access to preventive services has been found in previous research to be associated with income. ${ }^{10.12 .22}$ This relationship is not surprising. In our present health care system, where virtually no insurance coverage exists for preventive care visits to physicians, higher income people are more likely to have established a regular relationship with a provider of care, which facilitates the receipt of preventive care. Hence, we include a direct, positive causal path from income to usual source of care in our model.

Researchers are just beginning to explore the relationship between income and health beliefs. We have a priori specified income to influence a person's perceptions of his or her susceptibility to illness, of the severity of illnesses, and of the efficacy of preventive medical care. These specifications are derived from the concept of the culture of poverty which, applied to this issue, says that people differ in their attitudes toward health and health care by income level. ${ }^{29.30}$ Although preventive health behavior has been shown to be related to health beliefs, ${ }^{31}$ there is a good deal of debate about both the existence of the relationship between health beliefs and income and the importance of those beliefs in influencing utilization, compared to the significance of access differentials and financial constraint differentials. Quite recently, Rosenstock ${ }^{32}$ has argued that health beliefs dominate other considerations in determining use, while Dutton ${ }^{21}$ has presented evidence that the influence of health related attitudes is overshadowed by the effect of differences in access. We take a middle course, grounded in economic theory, wherein use is determined jointly by peoples' preferences (or health beliefs) and by the financial and system constraints that they face.

Although it is well known that one's perceived health status is an important factor determining one's use of treatment services, very little is known of the relationship between this variable and use of physicians' services for monitoring and prevention. This issue has largely been ignored because it seems on the surface to be illogical. ${ }^{22}$ If one perceived oneself to be in relatively poor health, why not seek out treatment rather than preventive care? In fact this may often be the route chosen by such individuals when they can identify a symptom or other abnormality for which treatment can 
be sought. But in cases where one's evaluation of health status is more global, reflecting concern that one's general resistance to disease is low, one's response is likely to be to demand some assessment of one's health status. ${ }^{32}$ Hence, we include self-reported health status in the model and hypothesize that individuals who perceive themselves to be in relatively poor health will be more likely to use secondary preventive care. We also posit indirect effects of health status on use through the three health belief model variables. As one's health becomes poor one should perceive greater susceptibility to illness and greater severity of illnesses. In addition, poor health status may cause one to view preventive care as more efficacious.

As most typically formulated, the health belief model and other models of medical care use include socio-demographic variables which are thought to influence in some way the relationships between perceptions and utilization, or between income and utilization, or between access and utilization. The particular way in which these influences operate is not well specified. Instead, these variables are included as "control" variables in multiple regression models of use. In our model we have specified more clearly how we expect health beliefs, income, and access to combine with socio-demographic variables to influence the use of preventive services. As represented in Figure 1, we expect the sociodemographic variables to have both direct and indirect effects on secondary preventive health behavior.

There is surprisingly little empirical research on the relationships among socio-demographic characteristics, health beliefs, access, income, and use of preventive care. However, results from two early studies ${ }^{33.34}$ suggest that personal characteristics and health beliefs each make independent contributions to the use of preventive health care. Also, data from the national health survey reveal differences in physician visits for preventive care across a number of personal characteristics in the directions observed in the previous studies 35.36 In general, females, whites, and the well-educated are more likely to use preventive health care. Although the picture with regard to the role of age is less clear, it appears that from middle adulthood physician visits for preventive care increase with age. The following discussion will describe the hypothesized direct and indirect effects of age, family size, sex, education and race on use of preventive physician visits. Although these hypothesized relationships should be viewed cautiously, given the limited theoretical and empirical work on which they build, we feel they are reasonable assertions which are consistent with available evidence.

There are five indirect paths through which age may affect use. First, we expect older individuals to perceive themselves to be in 
relatively poor health, and, from what we have just argued, those in poor health will be more likely to use preventive services. Second, we expect income to increase with age; and income, as we have already discussed, will affect use in a variety of ways. The final three indirect paths through which age affects use are through the three health belief model variables: perceived susceptibility to illness, perceived severity of illness, perceived efficacy of physician visits for preventive care. Each of these should increase directly as a function of age. In addition to these indirect paths, we also posit a direct path between age to use. It seems reasonable to assert that as people get older they acquire the time and experience and the social reinforcement from friends and family which encourages them to seek out preventive care. There is some evidence to support this notion. Although not conclusive because of possible confounding effects of other variables, the zero order relationship betewen physician visits for preventive care and age is consistent with our assumption. National health survey data reveal that per capita visits to physicians for preventive care increase from .33 visits at age range 35-44 to .50 visits for those 75 years or older, with the exception of a drop in visits to .26 during the 65-74 age range (perhaps due to loss of employment-related health benefits upon retirement. $)^{26}$

Similar arguments are made for education and race of respondent. Higher education levels are hypothesized to be associated with higher family income, the perception of good health status, higher perceived susceptibility to and severity of illness and efficacy of preventive care. Additionally, we posit a direct, positive path from education to use. The zero order relationship between education and use observed in the national health survey supports this hypothesis. Preventive physician visits in 1971 increased with education from a low of 23 visits per capita for less than 5 years of education to .59 visits per capita for 13 or more years of education.

We expect white respondents to have higher incomes and to perceive themselves in good health. White respondents should also have higher perceived susceptibility, perceived severity of illness and perceived efficacy of preventive care. The direct path from race to use represents our expectation that white respondents are more likely to use preventive health care. ${ }^{26}$

The sex of the respondent also should have direct and indirect effects on use. We expect females to perceive themselves to be in poorer health than males and to have higher perceived susceptibility to and perceived severity of illness and higher perceived efficacy of preventive care. Also, we posit a direct path to use, expecting women to use preventive care more often than men. ${ }^{36}$

Finally, we hypothesize that the larger the size of one's family, the more constraining will be any particular level of income. 
Hence, we expect family size to be negatively related to use.

The theoretical model specified above can be tested with path analysis, which permits the disaggregation of total observed effects of the explanatory variables into 1) direct effects, 2) indirect effects through all the paths between the explanatory variable and the dependent variable, and 3) effects due to common correlation with other preceding variables in the model. Hence, path analysis is well-suited for testing the model of preventive use that is depicted in Figure 1. The test of the model which we shall employ rests upon the statistical significance of the path coefficients. If many of the path coefficients prove to be statistically significant, then the theoretical model would seem to have a good deal of validity. The path coefficients are simply standardized partial regression coefficients. The coefficients of the residual variables, $e_{\text {, in Figure }}$ 1 , estimate the predictive power of other unidentified exogenous variables (calculated as $1-R^{2}$, where $R^{2}$ is the square of the multiple correlation coefficient) ${ }^{37}$

\section{SOURCE OF DATA AND OPERATIONALIZATION OF VARIABLES}

The data for this analysis come from a household survey of adult residents of Washtenaw County. Michigan, conducted by the University of Michigan Health Services Research Center in 1977. The sample was obtained using a multistage sampling technique. The household units in the county were divided into segments. Five percent of the segments, containing 1,235 households, were randomly selected. From each household only primary adult respondents were selected and interviewed. A total of 854 interviews were completed (a 77.2 percent response rate). The 781 respondents analyzed here represent that portion of the sample for whom complete data were available.

Table 1 describes the categories, means, and standard deviations of the variables in the model. The manners in which several of the variables were operationalized deserve specific comment.

The perceived health status variable $\left(X_{7}\right)$ reflects the respondents answer to the question:

Compared to other persons your age, where would you put yourself on this line, where a " 1 " means excellent health and a " 9 " means very poor health?

As a check on the validity of this measure, two other methods for operationalizing health status were also considered: 1) an illness index representing the number of days of restricted activity in a year; 2 ) a categorical variable indicating whether the person had a health problem which limited his or her activity. Essentially, the qualitative results for the model are independent of the measure of health status employed.

The perceived susceptibility to illness variable $\left(X_{8}\right)$ is an index computed by summing scores of responses to questions regarding one's perceived susceptibility to four diseases: heart disease, stroke, high blood pressure, and lung cancer. The wording of the question is: 


\begin{tabular}{|c|c|c|}
\hline Variable/Categor les & Mean & Stan. Dev. \\
\hline $\operatorname{sge}\left(x_{1}\right)$ & 40.02 & 15.85 \\
\hline Fam $1 l_{y}$ size $\left(x_{2}\right)$ & 2.73 & 1.53 \\
\hline $\begin{aligned} & \operatorname{sex}\left(x_{3}\right) \\
& 0=\text { male } \\
& l=\text { f cmale }\end{aligned}$ & .56 & .50 \\
\hline Educat ion $\left(X_{4}\right)$ & 13.39 & 3.05 \\
\hline $\begin{aligned} \text { Race } & \left(x_{5}\right) \\
0 & =\text { nonwhite } \\
1 & =\text { white }\end{aligned}$ & .92 & .27 \\
\hline 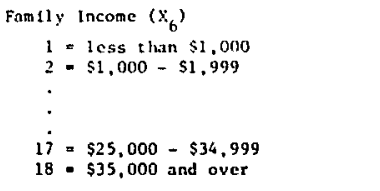 & 12.61 & 4.64 \\
\hline $\begin{array}{l}\text { Purceived Health Status }\left(x_{7}\right) \\
1 \text { - excellent } \\
9 \text { - very poor }\end{array}$ & 2.89 & 1.61 \\
\hline $\begin{array}{l}\text { P.arceived susceptibliticy }\left(x_{8}\right) \\
\text { High value = High Suscept ibility }\end{array}$ & 9.14 & 3.00 \\
\hline $\begin{array}{l}\text { Perceived Severity }\left(\mathrm{K}_{g}\right) \\
\text { High Value = High Severity }\end{array}$ & 16.80 & 2.40 \\
\hline $\begin{array}{l}\text { Perceived Efficacy of ND Visit }\left(x_{10}\right) \\
\text { High Value }=H i g h \text { Efficacy }\end{array}$ & 12.48 & 3.49 \\
\hline $\begin{array}{l}\text { Usual Source of Care }\left(X_{11}\right) \\
\qquad \begin{array}{l}0=\text { No } \\
1=\text { Yes }\end{array}\end{array}$ & .79 & .41 \\
\hline Prevent tve :T visits per year $\left(x_{12}\right)$ & -85 & .61 \\
\hline
\end{tabular}

How likely do you think it is that you could get (disease) in the next five years? Would you say it is very likely (4), somewhat likely (3), not very likely (2) or not at all likely (1)?

If the respondent had one of the four conditions, response was coded (5). Within the context of this study, this coding decision seems appropriate, because it reflects the fact that people who have one of the diseases feel susceptible to a worsening of their condition and therefore desire that their health status be monitored. The lowest possible score on this measure is 4 . Although a high of 20 is possible, the highest score observed in our sample is 18 .

The perceived severity of illness variable $\left(X_{9}\right)$ was similarly computed. The same four disease categories were used. The questions were asked as:

How much of an effect do you think it would make on a person's life if he or she had one of these diseases? Would you say a lot (5), quite a bit (4), some (3), a little (2), or none (1)?

Although a low score of 4 is possible, the lowest score observed is 7 . The highest is 20.

Perceived efficacy of physician visits for preventive care $\left(X_{10}\right)$ is measured across the same disease categories. The questions were phrased as: 
How much do you think a doctor, dentist, or some other health professional can do to prevent (disease). Would you say nothing (1), a little (2), some (3), quite a bit (4), or a lot (5)?

Ideally, these questions should have asked people whether the provider could prevent disease or further disease once a health status problem was detected. A low of 4 and a high of 20 are observed with this sample

Usual source of care $\left(X_{11}\right)$ is a dummy variable coded zero if respondents indicate no usual source and coded one if some kind of usual source of care (private practitioner, private clinic, outpatient clinic, emergency room, etc.) is indicated.

Number of physician visits for preventive care $\left(X_{12}\right)$ is measured with the following question:

\begin{abstract}
About how often do you visit a physician for a checkup even though you may be feeling well? Would you say at least once every six months, once a year, once every two years, less than once every two years, or have you never gone for a checkup?
\end{abstract}

The categories were transformed for analysis into annual visit rates of $2,1, .5, .25$, 0 . The intent here is to discover how frequently people have their health status monitored.

\title{
RESULTS
}

The estimated path coefficients for the model are indicated in Figure 1 as well as in Table 2. In general, the model seems to have been reasonably well formulated. The equation for use of preventive services explains 20 percent of the variation. Nearly all of the independent variables proved to be significantly related to use in the direction hypothesized. As specified, use of physicians services for prevention appears to be influenced by people's perceptions, by their access to health care, by their health status, and by their personal characteristics. Contrary to our expectations, income does not appear to affect use by acting as a financial constraint. However, income does affect use in other ways, as discussed below.

People's health beliefs, or perceptions, influence their use of preventive services directly. People who perceive themselves to be more susceptible to the illnesses in question use more preventive services. Also, people who think that preventive visits to an M.D. are efficacious get more preventive care. Hence, persons who feel susceptible to disease and believe that preventive care is worthwhile engage in significantly more secondary preventive health behavior. These results coincide with those of a previous study of preventive utilization ${ }^{31}$ and reinforce other evidence on the importance of these preceptions. The other health belief variable, perceived severity of disease, is negatively related to use of preventive services, contrary to expectation. In previous research, per- 


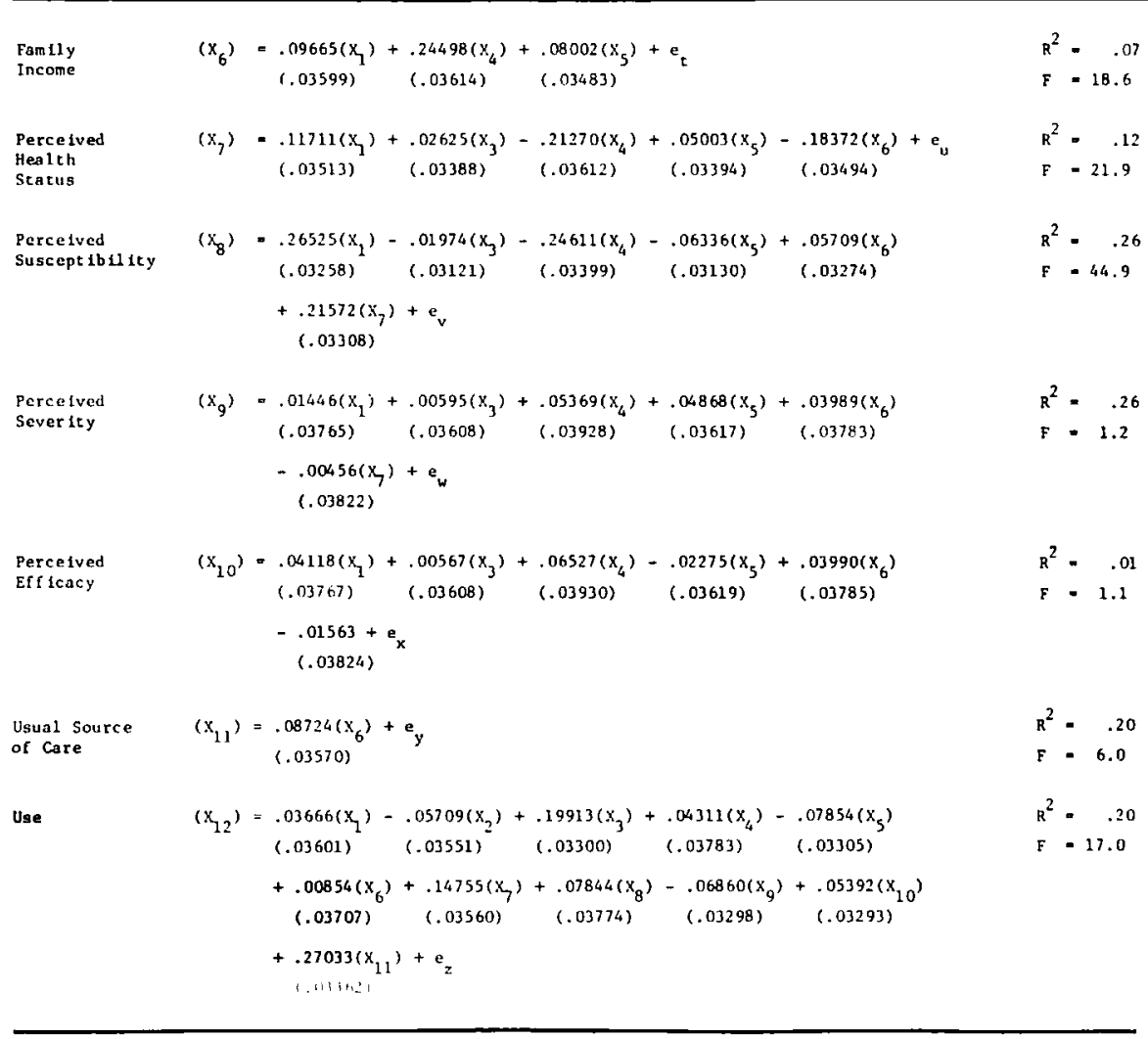

ceived severity has been found to be unrelated to preventive use. ${ }^{31.32}$

Access to health care, as measured by whether or not the person has a usual source of care, also influences use of preventive services directly. In fact, access, or absence of barriers, is the variable with the strongest effect on use. This result supports recent findings for preventive use by children. ${ }^{22}$

Perceived health status affects frequency of physician visits for prevention in two ways. First, persons with lower perceived health status use more preventive services. This direct effect of health status on use is relatively large, being exceeded in magnitude only by the effects of access and sex. This result contradicts that of Wan and Gray for children. ${ }^{22}$ The second manner in which health status influences use is through people's health beliefs. In particular, people with low perceived health status believe themselves to be more susceptible to further illness than people in good health. And, as already reported above, perceived susceptibility to illness is 
positively associated with use of preventive services. The magnitude of the indirect effect of perceived health status on preventive use through perceived susceptibility is equal to the product of the coefficient of perceived health status on perceived susceptibility and the coefficient of perceived susceptibility on use, or $.21572 \mathrm{x}$ $.07844=.01692$. Compared to the direct effect of perceived health status on use, which equals .14755 , this indirect effect is rather small. However, a comprehensive assessment of the total effect of health status on use would account for this indirect effect. Hence, the total effect of perceived health status is the sum of the direct effect and the indirect effect, or .14755 $+.01692=$ .16447 . Table 3 presents a compilation of the direct, indirect, and total effects of all the independent variables in the model on preventive services utilization.

Income is perhaps the most interesting independent variable in terms of its effects on use of preventive services. Contrary to our hypothesis, there appears to be no direct relationship between income and use; that is, low income does not act as financial constraint which inhibits use of this type of preventive care. There are, however, significant and contradictory indirect effects of income. First, our results indicate that higher income is associated with having a usual source of care, which in turn increases frequency of preventive visits. Second, higher income people have better perceived health status, which is related to a reduced consumption of preventive services. Finally, increased income raises a person's perceived susceptibility to illness, which causes the person to use more preventive services. These three indirect effects of income on preventive use are in directions and magnitudes such that they virtually cancel each other out, making the total effect of income on use negligible. Of course, this is not to say that income does not influence use of preventive services. Rather, income does not effect utilization, positively by improving access and increasing perceived susceptibility and negatively by raising health status. The relationships among income and the other model variables have been the subject of a separate analysis and report. For further discussion of this, see Rundall and Wheeler. ${ }^{38}$.

Many of the sociodemographic variables also appear to influence preventive utilization directly, indirectly, or both. Age is similar to income in that while it has no direct effect on use, it has two fairly large indirect effects. First, age is associated with lower health status, which increases use of preventive services. Second, aged people perceive themselves to be more susceptible to illness and hence use more preventive care. Therefore, while a study of the direct relationship between age and preventive use suggests that age has no effect, a closer look at the way age affects use indirectly reveals a positive total effect. 
Usual Source of Care $\left(X_{11}\right)$

Direct (and Total) 1

.27033

Percelved Ef icacy ( $x_{10}$ ) Direct (and Total)

.05392

Perceived Severity $\left(x_{0}\right)$ Direct (and Total)?

Percelved Suscept lbllicy $\left(x_{8}\right)$ Direct (and tocal)

.07844

Perceived Health Status $\left(x_{7}\right)$

Diect

Indirect through $\left(x_{8}\right)$

.01692

Toral

Family Incone $\left(x_{6}\right)$

Ind irect through $\left(x_{11}\right)$

Indirect through $\left(x_{8}\right)$

Ind irect chrough $\left(x_{7}\right)$

Tota:

$(.08724)(.27033)=.02358$

$(.05709)(.07844)=.00447$

$(-.18372)(.16447)=-.03022$

$-.00217$

Race $\left(X_{g}\right)$

Direct

Indirect through $\left(x_{9}\right)$

Indirect through $\left(x_{B}\right)$

Indirect through $\left(x_{7}\right)$

Ind irece chrough $\left(X_{6}\right)$

Total

$-.07854$

$(.04868)(-.06860)=-.00334$

$(-.06336)(.07844)=-.00497$

$(.05003)(.16447)=.00823$

$(.08002)(-.00664)=-.00053$

Educat ton $\left(X_{4}\right)$

Indirect through $\left(x_{10}\right)$

Indirect through $\left(x_{9}\right)$

Indirect through $\left(x_{8}\right)$

Ind lrect through $\left(x_{7}\right)$

Indirect through $\left(x_{6}\right)$

Total

$\operatorname{sex}\left(x_{3}\right)$

Direct (and Total)

.19913

Family Size $\left(x_{2}\right)$

Direct (and Total)

$(.06527)(.05392)=.00352$

$(.05369)(-.06860)=-.00368$

$(-.24611)(.07844)=-.01930$

$(-.21270)(.16447)=-.03498$

$(.24498)(-.00664)=-.00163$

Age $\left(X_{1}\right)$

Indirect through $\left(x_{8}\right)$

Ind frect through ( $X_{y}$ )

Indirect through $\left(x_{6}\right)$ Total 
Like age, education has no direct effect on use, but has numerous indirect effects. The largest of these is the effect through health status. People with more education are healthier and hence use less preventive medical care. There is also a sizeable effect through perceived susceptibility. Educated people perceive themselves to be less susceptible to illness and hence use fewer preventive services. Therefore, while there is no apparent direct relationship between education and preventive use, a more detailed analysis reveals that more highly educated people, because they are less sick and perceive themselves to be less susceptible to illnesses, receive fewer checkups.

In contrast to age and education, the individual's sex affects use directly and strongly, but has no significant indirect effects because sex is unrelated to health beliefs or health status. The direct effect, which indicates that females use more preventive care than males, is second in magnitude only to the effect of accessibility of services.

Race also has principally direct effects on use. Interestingly, nonwhites use more preventive care than whites. The indirect effects through health status, income, and health beliefs are very small in comparison to the direct effect.

Finally, family size, specified to affect use only directly, proved to be negatively related. People in larger families use fewer preventive services, probably because for any given family income level, large families face more severe financial constraints, while classified as sociodemographic, actually have economic implications for use as preventive services.

\section{DISCUSSION}

Our analysis indicates that the frequency with which people see a physician for checkup is related both to people's perceptions of the benefits of such care and to the magnitude of various costs which must be borne in receiving care, where costs include overcoming barriers to access and financial constraints. People will use preventive medical care if they perceive themselves to be susceptible to illness and if they believe in the efficacy of these services. Also, they will use secondary preventive care if it is readily accessible to them because they have a usual source from which they obtain medical care. Our results are consistent with those of other studies which have focused on either the benefits or the costs side of the decision to use preventive services. ${ }^{22,21}$ But our findings go further by demonstrating that, when both perceptions of benefits and financial and access considerations are taken into account simultaneously, they both still matter. Therefore, the protracted 
debate over the appropriate model for explaining differentials in medical care use seems, from the perspective of these findings, to be ill-focused. The health belief model does explain some of the differences in preventive utilization. The presence or absence of barriers to the receipt of services does explain some of the differences in preventive utilization. Taken together these two influences explain more than either one does separately. Hence, a fully comprehensive model of preventive use should include both. For the same reason, an optimally effective public program to increase the use of preventive services should perhaps include both a health education component to apprise people of the efficacy of preventive care and of their susceptibility to preventable disease and an effort to improve access to preventive care for those persons who do not have a usual source of care.

In terms of the relative importance of access and health beliefs, our results suggest that the former is larger. Of course, this finding does not imply that most of the public effort to increase preventive utilization should go toward improving access. Such an allocation decision depends also upon the relative difficulty and costliness of improving access and of changing people's perceptions.

Our analysis provides some valuable information for the decision in the form of discovered relationships between personal characteristics and health beliefs. The nature of these relationships has not received close attention previously, so that the findings presented here should be considered exploratory. Perceived susceptibility to illness is strongly affected by a person's age, education, and health status. Aged people, less educated people, and people in poor health perceive themselves to be more susceptible to illness than others. In addition, perceived susceptibility is significantly but less strongly affected by family income and race, with high income people and nonwhites perceiving themselves to be more susceptible. Perceived efficacy of preventive care is influenced only by education. Higher education people believe that a preventive visit to a physician is worthwhile. Perceived severity of illness was found to be unrelated to any personal characteristics. As discussed earlier, the empirical relationship between use and perceived severity was contrary to our expectations. Both of these findings suggest either that the concept of perceived severity may not be meaningful or that it may be operationalized incorrectly.

Finally, our analysis has demonstrated that while a variable may have no obvious, direct relationship to utilization, it may have indirect effects which are important. Especially for income, age, and education, we found significant effects on use through intermediate variables, although no direct relationship was apparent. Previous studies which have examined only the direct effects of independent variables are deficient in this regard. The use of a path an- 
alytic model to explain use represents an improvement over these efforts and increases our understanding of the determinants of preventive care utilization.

\section{LIMITATIONS OF THE STUDY}

While we are encouraged by the results of our empircal test, we are also well aware that the model does not account for 80 percent of the variance in the dependent variable. This relatively low amount of explained variance is consistent with the pattern observed in the other large sample, multivariate studies cited above. In a recent paper, Mechanic ${ }^{16}$ discusses various theoretical and methodological reasons for this lack of explanatory power. One possibility is the crude measurement of key variables often associated with survey research. For example, we measure health status by a subjectively reported ranking on a nine point scale. Such a measure taps a more complex pattern of illness perception that we ideally would like to include in a measure of morbidity. When such a proxy measure of morbidty is introduced in the regression equations, the influence of socio-demographic, attitudinal and behavioral variables may be reduced. Our measure of the dependent variable is subject to the same criticism. The question of whether one has received a medical checkup even though feeling well is open to differential interpretation by different people.

Another problem noted by Mechanic relates to the cross-sectional nature of most utilization research. As is typical of studies of its kind, our model makes assumptions about the direction of causal effects. In Figure 1, causation is assumed to proceed from left to right; but, since the data were collected at only one point in time, causation for at least some of the explanatory variables could proceed the other way-from use of preventive care toward variables such as usual source of care, perceived susceptibility to illness, etc. Longitudinal studies wherein the explanatory variables are collected prior to the observations of health behavior would help resolve this issue.

A third plausible reason for the low proportion of explained variance is that variables with significant explanatory power have been left out of the model. Unfortunately, models claiming to be comprehensive, including our own, may not be all that comprehensive. Obviously, work toward a more complete theory of health services utilization must continue. We hope that this paper stimulates refinement and further development of utilization models which integrate social-psychological and economic theories, because improved understanding depends upon this integration. 


\section{REFERENCES}

1. Coburn D, Pope CR: Socioeconomic Status and preventive health behavior. / Health Soc Behav 15:67, 1974

2. Becker $\mathrm{H}$ : The Health Belief Model and Personal Health Behavior. Thorofare, New Jersey: Charles B. Slack, Inc., 1974.

3. Acton JP: The demand for health care among the urban poor, with special emphasis upon the role of time, The Rand Corporation, 1973.

4. Anderson R, Aday LA: Access to medical care in the U.S.: realized and potential. Med Care 14:405, 1976.

5. Berki SE; Kobashigawa B: Path analysis of the 1970 health interview survey data. Med C 14:405, 1976.

6. Phelps C. Newhouse JP: Coinsurance, the price of time, and the demand for medical services. Rev Econom Stat 56:334, 1974.

7. Andersen R: A behaviora! model of families' use of health services, Research Series No. 25. Chicago: Center for Health Administration Studies, University of Chicago, 1968.

8. Andersen R, Newman JF: Societal and individual determinants of medical care utilization in the United States. Milbank Memorial Fund Q 51:95, 1973.

9. Wan T, Soifer SI: Determinants of physician utilization: a causal analysis. / Health Soc Behav 15:100, 1974.

10. Andersen R: Health service distribution and equity. In R Andersen, I Kravits, and OW Anderson (eds.) Health Services: Empirical Analyses in Social Policy, Cambridge: Ballinger Publishing Co., 1975.

11. Kronenfeld J: Provider variables and the utilization of ambulatory care services. I Health Soc Behav 19:68, 1978.

12. Wolinsky FD: Assessing the effects of predisposing, enabling and illness-morbidity charteristics on health service utilization. / Health Soc Behav 19:384, 1978

13. Galvin ME, Fan M: The utilization of physician services in Los Angeles County, 1973. I Health Soc Behav 16:74, 1975.

14. Hershey IC, Luft HS, Gianaris IM: Making sense out of utilization data. Med Care 13: 838, 1975.

15. Berki SE, Ashcraft ML: On the analysis of ambulatory utilization. Med Care 17:11631181, 1979.

16. Mechanic D: Correlates of physician utilization: Why do major multivariate studies of physician utilization find trivial psychosocial and organization effects? / Health Soc Behav 20:387, 1979.

17. Shortell SM: Factors associated with the utilization of health services. In SI Williams and PR Torrens (eds.) Introduction to Health Services. New York: John Wiley and Sons, 1980 .

18. Becker MH, Maiman L: Sociobehavior determinants of compliance with health andmedical care recommendations. Med Care 13:10, 1975.

19. Rosenstock IM: Why people use health services? Milbank Memorial Fund 44:94, 1966.

20. Becker MH, Haefner DP, Sasl SV.Kirscht JR, Maiman LA and Rosenstock IM: Selected psychosocial models and correlates of individual health-related behaviors. Med Care 15:27, 1977.

21. Dutton DB: Explaining the low use of health services by the poor: costs, attitudes, or delivery systems? Am Sociolog Rev 43:348, 1978.

22. Wan TTH, Gray LC: Differential access to preventive services for young children in lowincome urban areas. I Health Soc Behav 19:312, 1978

23. Andersen, $R$, and Benham, L: Factors affecting the relationship between family income and medical care consumption. In $\mathrm{H}$ Klarman (ed.) Empirical Studies in Health Economics. Baltimore: The Johns Hopkins University Press, 1970.

24. Feldstein, $P$, and Carr, J: The effect of income on medical care spending. In Proceedings of the Social Statistics Section of the American Statistical Association, 1964.

25. Rosett, $R$, and Huang, $L$ : The effect of health insurance on the demand for medical care. fournal of Political Economy 81:281 1973.

26. National Center for Health Statistics, U.S. Department of Health Education and Welfare: Physician visits: volums and interval since last visit, U.S., 1971. Vital and health statistics, ser. 10, No. 97, DHEW Publication No. (HRA) 75-1524. Washington. D.C.: U.S Government Printing Office. 
27. Luft HS: Poverty and Health: Economic Causes and Consequences of Health Problems. Cambridge: Ballinger Publishing Co, 1978.

28. Lerner $M$ : Social differences in physical health. In I Kosa and I Zola (eds.) Poverty and Health: A Sociological Analysis. Rev. ed. Cambridge: Harvard University Press, 1975.

29. Lewis O: The culture of poverty. Scientific Am 215:16, 1966.

30. Suchman EA: Health orientation and medical care. Am / Pub Health 56:97, 1966.

31. Rundall TG. Wheeler IRC: Factors associated with utilization of the swine flu vaccination program among senior citizens in Tompkins County. Med Care 17:191-200, 1979.

32. Rosenstock IM: The health belief model and preventive behavior. In M. Becker (ed) The Health Belief Model and Personal Health Behavior. Thorofare, New Jersey: Charles B. Slack, Inc., 1974. 